\title{
Estudo da competitividade da produção de algodão entre Brasil e Estados Unidos - safra 2003/04
}

\author{
Joaquim Bento de Souza Ferreira Filho ${ }^{1}$ \\ Lucilio Rogerio Aparecido Alves² \\ Patrício Mendez del Villar ${ }^{3}$
}

Resumo: O objetivo deste trabalho é analisar a competitividade da produção de algodão entre o Brasil e os Estados Unidos da América (EUA) com base nos custos de produção agrícola, tomando como referência a safra 2003/04. No Brasil, os dados foram coletados por meio de painéis com agentes do sistema produtivo, nas regiões de Campo Novo do Parecis (MT), Primavera do Leste (MT) e norte do Paraná. Os dados dos EUA são de fontes secundárias. Os resultados apontaram que, no Brasil, há maior competitividade, com alta produtividade, mas os custos considerados altos por hectare. $\mathrm{O}$ risco da cultura é elevado, devido às margens estreitas e aos sunk cost. Nos EUA, há menor produtividade, custos relativamente altos e margens negativas na maioria das regiões. Os dados indicam que a sustentabilidade do setor algodoeiro nos EUA é artificial, dependente de ajuda governamental.

Palavras-chaves: Algodão, custo agrícola, Brasil, Estados Unidos.

${ }^{1}$ Professor Titular do Departamento de Economia, Administração e Sociologia da Escola Superior de Agricultura "Luiz de Queiroz" (Esalq/USP). E-mail: jbsferre@esalq.usp.br

2 Professor do Departamento de Economia, Administração e Sociologia da Esalq/USP. Pesquisador do Centro de Estudos Avançados em Economia Aplicada (Cepea), da Esalq/USP. E-mail: lualves@esalq.usp.br

${ }^{3}$ Centro de Cooperação Internacional em Pesquisa Agronômica para o Desenvolvimento (Cirad), Departamento Meio Ambientes e Sociedades. Doutor em Economia Agro-Alimentar. Pesquisador da Unidade Mista de Pesquisa Territórios, Meio Ambiente, Monitoramento Sensorial e Informação Espacial(TETIS).E-mail: patricio.mendez@cirad.fr 


\title{
Classificação JEL: M11, O13, Q12.
}

\begin{abstract}
This study aims to analyze the competitivity of the cotton production in Brazil and United States of America (USA) in terms of production costs, taking into consideration the 2003/04 crop season. In Brazil, data were colleted in "panel conferences" in the state of Mato Grosso (Campo Novo do Parecis and Pimavera do Leste) and also in the north of the Parana state. USA's data came from secondary sources. The results showed that Brazil has a better competitivity, with good productivity, but high costs per hectare. The risk of the culture is high, given the short margins and the sunk costs. In USA, the average productivity is smaller than in Brazil; the costs are relatively high and the margins are negative in most regions. Results show that the sustainability of the cotton industry in USA is artificial, and dependent of government support.
\end{abstract}

Key-words: Cotton, production costs, Brazil, United States.

JEL Classification: M11, O13, Q12.

\section{Introdução}

O objetivo deste trabalho é analisar a competitividade da produção de algodão entre o Brasil e os Estados Unidos da América com base nos custos de produção agrícola de regiões selecionadas, tendo como referência a safra 2003/04. Tomou-se como base a referida safra visto que era a última com dados consolidados para os Estados Unidos, quando elaborou-se este trabalho. Para comparação com os dados dos EUA, a coleta de informações no Brasil ocorreu em três regiões do estado de Mato Grosso (Primavera do Leste, Lucas do Rio Verde e Campo Novo do Parecis), onde a produção de algodão envolve alta tecnologia, e uma no estado do Paraná (para áreas com colheitas mecânica e manual), em que a maior parte das propriedades utiliza tecnologia intermediária.

Nos últimos anos, ocorreu um acréscimo expressivo da produção mundial de algodão. Um dos primeiros impactos desse aumento deu-se sobre os preços da fibra. Ao mesmo tempo, observaram-se freqüentes altas nos custos dos insumos para produção. Enquanto variações de mercado estão fora do controle do produtor, este pode melhorar sua perspectiva da cultura por meio de controle dos custos de produção. Além disso, para manter a rentabilidade, produtores precisam investir em 
novas tecnologias, em melhoramento genético (novas variedades) e em tratamentos que proporcionem menores custos de produção por unidade produzida.

Em âmbito internacional, a competitividade é afetada por diversos fatores, de ordens tecnológica e mercadológica. Atualmente, os principais países produtores utilizam sementes de algodão geneticamente modificadas (GM), o que pode implicar em vantagens para os mesmos. Adicionam-se, também, os subsídios destinados tanto para o plantio quanto à exportação dados por alguns países, em especial os Estados Unidos da América (EUA). Esses aspectos podem interferir direta ou indiretamente nos custos de produção, na oferta do produto, nos preços de venda e, conseqüentemente, na rentabilidade do produtor.

Considera-se, da mesma forma, o fim das cotas do Acordo de Têxteis e Vestuários (ATV), em janeiro de 2005, o qual tinha por objetivo a eliminação gradual, por 10 anos, das restrições ao comércio de têxteis e vestuários (cotas). Este novo contexto deverá fazer com que se acirre a concorrência entre os países no âmbito de produção de matéria-prima e de produtos acabados. Como participante importante deste mercado, o Brasil precisa se posicionar como fornecedor confiável e sempre visar produzir fibra de boa qualidade.

Além dessas considerações iniciais, este trabalho conta, ainda, com outras cinco seções. Na segunda seção, é apresentada a metodologia utilizada para obtenção das informações e cômputos dos custos de produção nas regiões analisadas, assim como a estrutura de formação do custo. Em seguida, nas seções 3 e 4, são feitas breves considerações sobre os sistemas de produções no Brasil e nos EUA. Os resultados e discussões constam na seção 5 .

\section{Metodologia}

\subsection{Análise de competitividade: aspectos teóricos}

Quando se fala do termo competitividade, existem diversos meios de abordá-lo, caracterizando países, setores econômicos e empresas. Entre as formas de se mensurar competitividade, alguns indicadores podem ser considerados, como os de desempenho, de eficiência e de capacitação.

Segundo Coutinho et al. (1993), os indicadores de desempenho geralmente se referem à participação do agente no ambiente sob análise. 
Os indicadores de eficiência e de capacitação explicam o desempenho do agente estudado. Para analisar os indicadores de eficiência, relacionam-se preços e custos dos bens e serviços comercializados, incluindo a produtividade técnica e econômica no uso dos fatores de produção. Para isto, podem-se comparar custos, preços, coeficientes técnicos e/ou produtividade dos fatores. Nos indicadores de capacitação incluem-se fatores determinantes do sucesso competitivo do agente estudado. Neste caso, vários são os itens que podem ser analisados. A capacitação pode estar relacionada aos avanços tecnológicos em produtos e processos, às inovações organizacionais da empresa, ao modo de se relacionar com outros agentes e ao nível de investimentos, inclusive em "capital humano".

Desta forma, se poderia utilizar aspectos relacionados a custos para identificar a eficiência e, consequentemente, a competitividade da produção de algodão no Brasil, comparativamente a outros países. Entretanto, segundo Kupfer (1996), as visões que associam competitividade com fatores que levam a chamada competitividade revelada, envolvendo análises de desempenho em termos de market-share, lucratividade, relação preço-custo, etc., são extremamente malsucedidas em relação a sua capacidade de explicar como a competitividade de uma empresa, setor ou nação evolui ao longo do tempo. Os defensores da abordagem da competitividade pelo ângulo da eficiência produtiva - a chamada competitividade potencial - tampouco superam esse problema.

Diante das diversas discussões sobre competitividade e sua mensuração, Kupfer (1996) aponta que competitiva é a empresa e/ou setor que consegue formular e implementar estratégias concorrenciais, que lhe permitam ampliar ou conservar, de forma duradoura, uma posição sustentável no mercado.

Segundo Müller (2006), competitividade é o conjunto e condições requeridas para o exercício da concorrência. Da mesma forma, Duren; Martin; Westgren (1994) descrevem que competitividade é a habilidade de se obter lucros e manter a participação nos mercados. Com isso, faz-se uma conexão com sustentabilidade, ou seja, obtendo lucros, é possível cobrir os custos variáveis e fixos da atividade e se manter no mercado.

É nesta linha que este trabalho visa analisar a competitividade da produção de algodão entre Brasil e Estados Unidos. Para que o produtor possa se manter na atividade, é mister que seu custo seja inferior ao de seus concorrentes, além de buscar rentabilidade positiva sobre os 
investimentos necessários. Nesta linha, Barros (2007) descreve que a gestão no mundo globalizado, em que a atividade produtiva interliga-se fortemente com questões comerciais e financeiras, precisa assumir uma forma dinâmica e flexível. O acompanhamento e análise de custo de produção se fazem condições essenciais.

\subsection{Coleta de dados e a técnica de painel}

Os dados no Brasil foram obtidos por meio de levantamento a campo, com técnica de painel ${ }^{4}$, distribuídos entre dois sistemas: um mais tecnificado, podendo ser denominado "sistema empresarial" e outro de técnicas de produção chamada "intermediária". Para o sistema empresarial, foram realizados dois painéis no estado de Mato Grosso, sendo um em Primavera do Leste (PL) e outro em Campo Novo do Parecis (CNP). Para o sistema intermediário, os dados foram obtidos no norte do estado do Paraná, para sistemas de plantios direto e convencional e colheitas mecânica e manual.

A coleta de dados através de painel é caracterizada por reuniões entre um grupo seleto de produtores, técnicos, pesquisadores e comerciantes, representativos das regiões sob análise. No painel, os participantes discutem, em conjunto, e procuram desenhar um sistema típico de produção de determinada localidade. Todos os passos do custo são detalhados: os equipamentos, sua potência e consumo de combustível por unidade de tempo; os coeficientes técnicos dos equipamentos, em especial o número de horas necessárias por hectare para a realização de determinado trato cultural; os insumos utilizados, com seu princípio ativo, quantidade e preço pago; entre outros. Durante as discussões, o grupo prepara uma planilha de custo que representará uma situação típica da região.

Foram incluídos os custos financeiros e de arrendamento da terra. Nesses casos, o objetivo era determinar uma proxy para o custo que o agricultor incorreria com a tomada de financiamento para custeio e para o custo de oportunidade da terra, respectivamente, para fins de comparação com os EUA. Desta forma, o custo de arrendamento foi considerado como o custo de oportunidade de se plantar algodão. Caso o produtor optasse por não cultivar algodão, poderia arrendar sua propriedade para outro interessado e obter recursos com este

\footnotetext{
${ }^{4}$ Mais informações sobre descrição de painel e outras características podem ser verificadas em De Zen \& Peres (2002) e Plaxico \& Tweeten (1963).
} 
- Estudo da competitividade da produção de algodão entre Brasil

e Estados Unidos - safra 2003/04

arrendamento. Por outro lado, caso a produção e algodão resultasse em prejuízo, o arrendamento poderia gerar recursos acima daquele obtido com a cultura do algodão.

Não se computam os custos com a remuneração de fatores fixos, como depreciação de instalações diversas, remuneração e o custo de oportunidade do empresário. Contudo, são adicionados os custos com depreciação de máquinas e equipamentos utilizados diretamente na atividade. Os itens considerados são mais característicos aos processos produtivos e, portanto, menos heterogêneos entre produtores. Os painéis nas regiões brasileiras foram realizados na última semana de julho de 2004, quando o processo de colheita já estava na fase final em Mato Grosso e já havia finalizado no Paraná.

Para cálculo dos custos por libra-peso e por hectare, considerou-se um rendimento de pluma de 39\% para as regiões de PL e CNP e de 36\% para o Paraná. Também foram adicionados os gastos com a Contribuição Especial da Seguridade Social Rural (CESSR) ${ }^{5}$, no valor de 2,3\%. No cômputo das margens de vendas, também por libra-peso e por hectare, foi considerado um preço médio pago para retirar a pluma da região, no período de janeiro a julho de 2004, segundo informações do Centro de Estudos Avançados em Economia Aplicada (Cepea/Esalq-USP, 2005). A metodologia base consiste em subtrair do Indicador CEPEA/ESALQ de algodão em pluma os fretes da região de origem até a cidade de São Paulo.

Os dados dos Estados Unidos foram levantados por meio de fontes secundárias, pela internet, com base no USDA (2006a). Estas informações foram agrupadas em itens que permitissem a comparação entre os países. Para este trabalho, os dados de custos estarão subdivididos em cinco grandes regiões: Heartland, Prairie Gateway, Southern Seaboard, Fruitful Rim e Mississippi Portal, além de uma média para os EUA.

Para cálculo das receitas brutas e das margens (receita total subtraída do custo total), foram considerados os preços médios descritos na Tabela 1 e na Tabela 2, que se referem ao valor recebido por produtores em cada região. Todos os preços referem-se ao tipo base 41-4. Para efetuar a comparação do custo de produção de algodão entre Brasil e EUA, calcularam-se os custos em dólar das regiões brasileiras, considerando a

\footnotetext{
Esta denominação equivale ao antigo Fundo de Assistência ao Produtor Rural (Funrural). O valor é descontado do produtor rural quando efetua vendas de produtos para cooperativas, industriais e comerciantes, entre outros. O recolhimento é feito pelo comprador. A verba descontada deve estar discriminada na nota fiscal. Os negócios praticados entre produtores rurais não estão sujeitos ao recolhimento da taxa.
} 
taxa de câmbio (em R\$/US\$) média entre os meses de setembro de 2003 e agosto de 2004, período de aquisição e pagamento dos insumos, que foi de $\mathrm{R} \$ 2,9528 / \mathrm{US} \$ 1,00$.

\section{Caracterização dos sistemas de produção no Brasil}

Entre a segunda metade da década de 1980 e meados da década de 1990, o plantio de algodão no Brasil teve decréscimo expressivo, com reflexos diretos no volume produzido e nas importações. A produção foi diminuindo até a safra 1996/97, enquanto as importações foram crescentes no mesmo período. A partir da safra 1998/99, a produção passou a apresentar sinais de recuperação. Com o consumo relativamente estabilizado no mercado interno, a maior produção resultou em excedentes de oferta, favorecendo a exportação e reduzindo a necessidade de importação. Atualmente, pode-se dizer que o Brasil possui um papel importante tanto em termos de produção quanto de exportação mundiais de algodão, participando com 6,3\% e 3\%, respectivamente, desses mercados na safra 2003/04.

As mudanças proporcionaram, de um lado, a ameaça daquela cotonicultura que atendia a um paradigma produtivo tradicional, tal seja, intensiva em mão-de-obra e, muitas vezes, pouco tecnificada (estados de Paraná e São Paulo, por exemplo). De outro, passou a ocorrer o desenvolvimento relativamente recente da "cotonicultura empresarial" abrangendo áreas principalmente no Centro-Oeste do País e em algumas outras regiões, como o Sudeste (Minas Gerais) e Nordeste (Bahia), a qual é praticada em grandes extensões, capitalizada e tecnificada. Na safra 2003/04, os principais estados produtores, em ordem decrescente, foram: Mato Grosso (46,8\% do total de algodão em pluma), Bahia (20,3\%), Goiás (13\%), Mato Grosso do Sul (5,7\%), São Paulo (5,3\%), Minas Gerais (3,7\%) e Paraná $(2,5 \%)$.

Regionalmente, entre as principais regiões produtoras de algodão no ano de 2004 no Brasil, destacam-se as mato-grossenses do meio-norte (Lucas do Rio Verde), Campo Novo do Parecis e Rondonópolis; da Bahia, Luiz Eduardo Magalhães; e o sudoeste goiano (Rio Verde, Mineiros e Chapadão do Céu). No Paraná, as regiões norte e noroeste do estado são as mais importantes. Desta forma, as regiões consideradas neste estudo são representativas quanto aos sistemas de produção brasileiros. 
É expressiva a relação entre o acréscimo de produção e de produtividade na cotonicultura nacional em todas as regiões. Desde a segunda metade da década de 1970, a produtividade brasileira está em ascensão, mesmo nos períodos em que a área decresceu. Mas, foi no final dos anos 1990, com o deslocamento da produção para novas regiões, que a quantidade produzida por unidade de terra deu o maior salto, ultrapassando as médias obtidas pelos principais países produtores. A produtividade agrícola de algodão em caroço, que nos 20 anos anteriores a 1985 estagnara-se abaixo de $600 \mathrm{~kg} / \mathrm{ha}$, em 1997, alcançou $1.400 \mathrm{~kg} / \mathrm{ha} \mathrm{e}$, em 2004, ultrapassou $3.300 \mathrm{~kg} / \mathrm{ha}$. Este parece ser um dos principais fatores que contribuíram para a retomada da cotonicultura nacional ${ }^{6}$.

Para uma maior compreensão da dinâmica anual de plantio e de colheita de algodão no Brasil, algumas informações são adicionadas para realçar as diferenças regionais. O plantio de algodão inicia-se nos estados da região Centro-Sul, especificamente no Paraná, São Paulo, sul de Mato Grosso de Sul e norte de Minas Gerais, onde produtores plantam entre os meses de outubro e início de dezembro. Entre os meses de novembro e dezembro, o plantio se estende para o estado de Goiás, oeste e Triângulo Mineiro e Bahia. Em dezembro, ocorre também, o plantio no norte de Mato Grosso do Sul e o início das atividades em Mato Grosso, estendendo-se até fevereiro, nas regiões onde ocorre o plantio de algodão "safrinha". Nos meses de janeiro e fevereiro, efetua-se o plantio do algodão irrigado na Bahia e do sequeiro nos demais estados do Nordeste do País.

Com esses períodos de plantio, a colheita passa a ocorrer entre os meses de março e setembro de cada ano. Em geral, há concentração da colheita de junho a julho, período de pico de safra em Mato Grosso, Goiás e Bahia, principais produtores.

\subsection{Características do sistema produtivo em Mato Grosso e Paraná}

Nesta seção, serão apresentadas algumas características das regiões mato-grossenses de Primavera do Leste (PL) e Campo Novo do Parecis (CNP) e norte do Paraná, as quais serão as bases das análises no Brasil. Os principais dados para os sistemas de produção nessas regiões são apresentados na Tabela 1 .

${ }^{6}$ Mais uma análise dos aspectos que favoreceram a retomada da cotonicultura nacional pode ser encontrada em Alves (2006). 
As regióes de PL e CNP possuem processos altamente tecnificados, do plantio até a colheita. A propriedade típica produtora de algodão em PL é aquela que possui aproximadamente 5.600 ha, em média, plantando 3.000 hectares com algodão e, no restante da área, soja, milho e milheto. Em CNP, a propriedade típica considerada é de 3.000 ha, em que se plantam 1.000 hectares com algodão, sendo a diferença ocupada com soja (Tabela 1).

A totalidade do algodão plantado naquelas regiões é no sistema semidireto, na palha, ou seja, faz-se plantio de cobertura verde, com milheto, no período que antecede o de algodão. Nessas regiões, podem-se plantar variedades resistentes e/ou suscetíveis à doença azul, sendo que mais de $80 \%$ das áreas de algodão são compostas por variedades suscetíveis. Os dados dessas regiões se resumirão apenas aos referentes ao plantio de algodão com variedades suscetíveis à doença azul (Tabela 1).

No Paraná, atualmente, as regiões norte e noroeste são as maiores produtoras de algodão. Elas apresentam algumas realidades diferentes em termos de características dos produtores e métodos utilizados no processo produtivo do algodão. Há plantio na forma convencional e uma pequena parcela no sistema de plantio direto, assim como colheitas mecânica e manual. Aqueles que efetuam a colheita mecânica geralmente cultivam áreas maiores de algodão e obtém maior produtividade. A colheita manual é realizada por pequenos produtores, que utilizam mão-de-obra familiar. A quase totalidade do plantio de algodão é feita com variedades resistentes à doença azul.

Diante das características distintas de processos produtivos, optou-se por considerar pelo menos dois sistemas de produção no Paraná. O sistema mais comum encontrado é o de plantio convencional, com colheitas manual e mecânica. Para aqueles que utilizam a colheita mecânica, a propriedade típica considerada foi de uma fazenda com 120 ha, destinando 50 hectares para algodão. No restante das áreas, podem ser encontrados plantios de soja, milho, café, mandioca e pastagens, neste caso, em uma pequena área (Tabela 1).

A propriedade típica para colheita manual é aquela que possui até 36 ha, dos quais 15 hectares seriam utilizados com algodão. Nas demais áreas há lavouras de soja, milho, café, mandioca e também atividades de pastagens. 
Tabela 1. Principais características dos sistemas produtivos considerados nas regiões brasileiras - safra 2003/04

\begin{tabular}{|c|c|c|c|c|}
\hline \multirow{2}{*}{ Itens } & \multirow{2}{*}{ PL } & \multirow{2}{*}{$\mathrm{CNP}$} & \multicolumn{2}{|c|}{ PR } \\
\hline & & & Sist. $1^{*}$ & Sist. $2^{* *}$ \\
\hline Variedades & Susceptível & Susceptível & Resistente & Resistente \\
\hline Plantio & Semi-direto & Semi-direto & Convencional & Convencional \\
\hline Colheita & Mecânica & Mecânica & Mecânica & Manual \\
\hline $\begin{array}{l}\text { Produtiv. algodão } \\
\text { em caroço }(\mathrm{kg} / \mathrm{ha})\end{array}$ & 3.600 & 3.750 & 3.000 & 2.500 \\
\hline Área Propriedade (ha) & 5.600 & 3.000 & 120 & 36 \\
\hline Área com algodão (ha) & 3.000 & 1.000 & 50 & 15 \\
\hline Outras culturas & $\begin{array}{l}\text { Soja, milhoe } \\
\text { milheto }\end{array}$ & Soja e milho & $\begin{array}{l}\text { Soja, milho, } \\
\text { pastagem, café, } \\
\text { mandioca }\end{array}$ & $\begin{array}{l}\text { Soja, milho, } \\
\text { pastagem, café, } \\
\text { mandioca }\end{array}$ \\
\hline $\begin{array}{l}\text { Preço de venda } \\
\text { (US\$/lp) }\end{array}$ & 0,6468 & 0,6543 & 0,6472 & 0,6472 \\
\hline $\begin{array}{l}\text { Rendimento } \\
\text { de fibra }(\%)\end{array}$ & 39 & 39 & 36 & 36 \\
\hline
\end{tabular}

Fonte: Dados da pesquisa

* plantio convencional e colheita mecânica;

** plantio convencional e colheita manual;

*** para o tipo base $41-4$.

\section{Caracterização dos sistemas de produção nos Estados Unidos}

A produção de algodão dos Estados Unidos está subdividida em praticamente 17 estados, localizados entre a costa Leste, passando pelo Sul do país, até a Região Oeste. Entre os maiores estados produtores destacam-se o Texas, que representou, em média, 26,2\% da produção daquele país entre as safras 1990/91 e 2003/04. Apenas para efeito de comparação, somente este estado produziu o equivalente a 72,7\% (952,3 mil toneladas) da quantidade total produzida pelo Brasil no ano-safra 2003/04 (1.309,4 mil toneladas). Outros estados também se destacam na produção de algodão, como: Mississippi, Geórgia, Califórnia, Arkansas, Carolina do Norte, Louisiana e Tennessee.

Como não há dados separados sobre custos de produção em nível estadual, mas somente por regiões características nos Estados Unidos, vale a pena descrever os dados de cada região quanto à aptidão agrícola, representatividade no total de propriedades, valor da produção, entre 
outros. Para isso, toma-se como base dados do Departamento de Agricultura dos Estados Unidos (USDA), de 2000, que subdivide o país em nove regiões agrícolas, sendo: ${ }^{7}$

- Basin e Range: representam $4 \%$ das propriedades do país, $4 \%$ do valor da produção e $4 \%$ das terras agricultáveis;

- Fruitful Rim (oeste, sul do Texas e Flórida): representa 10\% das propriedades, $22 \%$ do valor da produção e $8 \%$ das terras agricultáveis. As maiores produções da região são de frutas, vegetais e algodão;

- Prairie Gateway (Sudoeste): representa 13\% das propriedades, $12 \%$ do valor da produção e $17 \%$ das terras agricultáveis. As maiores produções da região são de trigo, algodão, sorgo, arroz e pecuária;

- Mississippi Portal: representa 5\% das propriedades, 4\% do valor da produção e $5 \%$ das terras agricultáveis. As maiores produções da região são de algodão, arroz, pecuária e suínos;

- Southern Seaboard (Sudeste): representa 11\% das propriedades, $9 \%$ do valor da produção e $6 \%$ das terras agricultáveis. As maiores produções da região são de pecuária, grãos em geral e aves;

- Eastern Uplands: representa 15\% das propriedades, 5\% do valor da produção e $6 \%$ das terras agricultáveis. As maiores produções da região são de pecuária, aves e fumo (tabaco);

- Northern Crescent: representa 15\% das propriedades, $15 \%$ do valor da produção e $9 \%$ das terras agricultáveis. As maiores produções da região envolvem gado de leite, produções gerais e grãos diversos para fins comerciais;

- Heartland (Missouri bootheel): representa 22\% das propriedades, $23 \%$ do valor da produção e $27 \%$ das terras agricultáveis. As maiores produções da região são de grãos diversos para fins comerciais e pecuária;

- Northern Great Plains: representa 5\% das propriedades, 6\% do valor da produção e $17 \%$ das terras agricultáveis. As maiores produções da região são de trigo, pecuária e caprinos.

Conforme a distribuição dessas regiões, os principais estados produtores de algodão enquadram-se nas regiões Prairie Gateway, Fruitful Rim, Mississippi Portal e Southern Seaboard. Essas regiões estão

\footnotetext{
7 A divisão regional das propriedades agrícolas dos EUA, segundo suas características, pode ser encontrada em Brooks (2001).
} 
inseridas nas quatro principais regiões produtoras de algodão de terras altas (upland) do país, sendo: Sudeste, Centro-Sul, Sudoeste e Oeste, as quais coletivamente são chamadas de Cinturão do Algodão(Cotton Belt).

Dentro dessas regiões, a do Sudeste representa aproximadamente $19 \%$ da produção de algodão de terras altas. O período de plantio é de início de abril a início de junho, com colheita entre final de setembro e início de dezembro.

Aproximadamente $34 \%$ do algodão são plantados no Centro-Sul e o plantio nesta região inicia em meados de abril e termina no final de junho. A colheita ocorre de início de setembro a início de dezembro.

O Sudoeste norte-americano é composto por Kansas, Oklahoma e Texas, representando $31 \%$ da produção de algodão. O plantio no sul do Texas inicia-se no final de fevereiro, com colheita ocorrendo de final de julho até meados de setembro. Nos demais estados, o plantio geralmente inicia a partir de meado de abril, para colher de final de outubro a dezembro.

Por fim, a região Oeste representa $13 \%$ do algodão de terras altas produzido nos EUA. O plantio começa no início de abril, estendendo-se até início de junho. A colheita ocorre entre final de setembro e início de dezembro.

Quanto ao sistema de plantio, o mais comum utilizado é o que se planta em duas linhas e se pula uma. Entretanto, boa parte do algodão norte-americano também é plantada em fileira única (solid rows).

A colheita nos EUA é realizada de duas formas. Alguns utilizam colhedoras do tipo strippers, enquanto outros usam o sistema convencional, em módulo (module builders), com colhedoras chamadas pickers. Este último sistema é semelhante ao usado no Brasil, em que, após a colheita, o algodão em caroço é colocado na prensa, sendo transformado em fardos ou módulos de aproximadamente 10 mil quilos, da extensão de um caminhão estilo carreta. Em seguida, esses módulos são cobertos com lonas plásticas, sendo levados para beneficiamento somente quando a algodoeira estiver necessitando. As colhedoras strippers são aquelas que cortam a planta, que passa inteira pelo interior da máquina, já sofrendo um processo de pré-limpeza, removendo sujeiras do algodão, como matos (carrapichos), madeiras, folhas, casca, areia e pedras.

Na Tabela 2 constam as principais características dos sistemas de produção de algodão nas principais regiões americanas, quais sejam: Heartland, Prairie Gateway, Southern Seaboard, Fruitful Rim e Mississippi Portal. Há, também, os dados médios para os EUA. 
Observa-se, inicialmente, que as áreas plantadas com algodão são maiores que as brasileiras, exceto em comparação com as de PL.

Em todas as regiões há uma parcela da área com produção de algodão irrigado, com destaque para a Fruitful Rim, onde está o estado da Califórnia, região semi-árida do país, que necessita de expressivo gasto com compra de água para irrigação. Esta área do país apresenta a maior produtividade média por hectare.

Tabela 2. Principais características dos sistemas produtivos das regiões dos EUA - safra 2003/04

\begin{tabular}{|c|c|c|c|c|c|c|}
\hline Itens & USA & Heartland & $\begin{array}{l}\text { Prairie } \\
\text { Gateway }\end{array}$ & $\begin{array}{l}\text { Southern } \\
\text { Seaboard }\end{array}$ & $\begin{array}{l}\text { Fruitful } \\
\text { Rim }\end{array}$ & $\begin{array}{l}\text { Mississip } \\
\text { pi Portal }\end{array}$ \\
\hline Variedades & \multicolumn{6}{|c|}{$76 \%$ foram de geneticamente modificadas em 2003} \\
\hline \multirow{2}{*}{ Plantio $\begin{array}{l}\text { Irrigado }(\%)^{*} \\
\text { Sequeiro }(\%)^{*}\end{array}$} & 33 & 33 & 30 & 11 & 74 & 30 \\
\hline & 67 & 67 & 70 & 89 & 26 & 70 \\
\hline Colheita & Mecânica & Mecânica & Mecânica & Mecânica & Mecânica & Mecânica \\
\hline $\begin{array}{l}\text { Produtiv. algodão } \\
\text { em caroço (kg/ha) }\end{array}$ & 2.177 & 2.533 & 1.039 & 2.438 & 3.201 & 2.832 \\
\hline $\begin{array}{l}\text { Área plantada } \\
\text { algodão (ha) }\end{array}$ & 1.829 & 2.207 & 1.888 & 1.322 & 1.517 & 2.511 \\
\hline $\begin{array}{l}\text { Preço de venda } \\
\text { (US\$/lp) }\end{array}$ & 0,66 & 0,65 & 0,61 & 0,64 & 0,71 & 0,65 \\
\hline $\begin{array}{l}\text { Rendimento } \\
\text { de fibra }(\%)\end{array}$ & 38,2 & 38,2 & 38,2 & 38,2 & 38,2 & 38,2 \\
\hline
\end{tabular}

Fonte: Dados da pesquisa.

* Participação sobre a área total plantada;

É importante salientar que não foi possível identificar as características e os custos separadamente entre o plantio de variedades GM - resistentes a insetos, herbicidas ou a ambos - e convencionais, e que os dados apresentados englobam ambas as variedades, sendo uma média para cada região. Sabe-se, contudo, que a maioria da área plantada com algodão naquele país é feita com variedades GM.

Variedades GM representaram $76 \%$ do algodão de terras altas plantadas nos EUA em 2003/04. No entanto, o uso de variedades GM em 2003/04 variou de 100\% de participação na Flórida a 42\% na Califórnia. No caso do Texas, maior estado produtor, as variedades GM representaram $56 \%$ da área plantada. 
- Estudo da competitividade da produção de algodão entre Brasil

e Estados Unidos - safra 2003/04

\section{Resultados}

\subsection{Análise comparativa dos custos de produção entre Brasil e Estados Unidos}

Nesta seção, será feita uma análise comparativa dos custos de produção entre Brasil e Estados Unidos. Inicialmente, os dados da Tabela 1 e da Tabela 2 mostram a maior produtividade agrícola de algodão em caroço nas regiões brasileiras, em especial as de Mato Grosso, comparativamente às dos EUA. Em termos de rendimento de fibra, há uma ligeira vantagem para os valores de CNP e PL (de 39\%) em relação aos norte-americanos $(38,2 \%)$. Os sistemas do Paraná são os que apresentam os menores rendimentos de fibra (36\%).

Analisando individualmente cada item, observa-se que nos custos com compra de sementes, na Tabela 3, todas as regiões brasileiras apresentam valor menor que as dos EUA. Além disso, ressalta-se a participação maior do custo com sementes nas regiões dos EUA, comparativamente às regiões brasileiras. Isso pode estar associado ao uso, naquele país, de sementes GM, que têm custo de aquisição maior. Contudo, essa análise deve ser feita com cautela, pois não se obtiveram informações sobre a quantidade de semente utilizada e tampouco do preço unitário de compra para os dados dos EUA.

Nos gastos com fertilizantes (Tabela 4), todas as regiões dos EUA apresentam valores menores que as do Brasil. A região Prairie Gateway, de menor custo com esse insumo nos EUA, apresentou um custo 78\% menor que as regióes paranaenses nos sistemas 1 e 2, de menor custo no Brasil. Observa-se que, enquanto esse custo tem uma participação entre $4 \%$ e $10 \%$ nas regiões dos EUA, nas regióes brasileiras seu peso varia entre $11 \%$ e $18 \%$.

Nas regiões brasileiras foi considerada uma aplicação de fertilizantes no plantio (de $300 \mathrm{~kg} / \mathrm{ha}$ no Paraná, de $400 \mathrm{~kg} / \mathrm{ha}$ em CNP e de $500 \mathrm{~kg} / \mathrm{ha}$ em PL) e de mais duas ou três com adubação de cobertura. Entretanto, dados do USDA (2006b) apontam que, em 2003, foram usados fosfatados somente em $52 \%$ das áreas plantadas com algodão nos EUA (em média de $56 \mathrm{~kg} / \mathrm{ha}$ ), em $82 \%$ foram utilizados nitrogenados (103 kg/ha) e, em $52 \%$, potássio (90 kg/ha). É esse contexto que favoreceu a competitividade dos EUA em relação às regiões brasileiras. 
Em gastos com defensivos químicos (Tabela 5), é expressiva a diferença entre os valores das regiões dos EUA e as do Brasil, com desvantagem realçada para as brasileiras. Esses valores também estão diretamente relacionados ao uso de semente GM, tolerante a herbicida e/ou resistente a insetos, nos EUA. Nas regiões de PL e CNP, esses custos representam aproximadamente $37 \%$ do custo total, enquanto nos EUA a participação dos defensivos oscilou entre $9 \%$ e $17 \%$ do custo total, que foi na região Mississippi Portal. Se a essa parcela for adicionada à referente ao uso de fertilizantes, chega-se a mais de $50 \%$ do custo total nas regiões de PL e CNP. Este resultado já começa a apontar em quais aspectos há maior competitividade dos EUA e desvantagem da produção brasileira.

Pode-se dizer que os gastos com máquinas (combustível, lubrificante, reparos e eletricidade; para o Brasil não foram computados os gastos com energia elétrica) apresentam uma expressiva divergência entre as regiões estudadas em relação ao valor monetário e ao peso deste item sobre o custo total (Tabela 6). A maior necessidade de capital fixo para irrigação em todas as regiões norte-americanas, principalmente na Fruitful Rim, assim como de máquinas e equipamentos de portes médios a altos, citados por NCAA (2004), contribui para os maiores valores e participação deste item nas regiões dos EUA.

Tabela 3. Custo de semente - safra 2003/04

\begin{tabular}{lcc}
\hline Região & Custo (US\$/ha) & Custo semente / custo total \\
\hline Estados Unidos & 91,90 & $7,5 \%$ \\
Heartland & 115,12 & $9,6 \%$ \\
Prairie Gateway & 71,81 & $9,2 \%$ \\
Southern Seaboard & 95,97 & $7,7 \%$ \\
Fruitful Rim & 67,41 & $3,8 \%$ \\
Mississippi Portal & 129,11 & $8,6 \%$ \\
Primavera do Leste & 61,87 & $3,6 \%$ \\
Campo N. Parecis & 50,17 & $3,3 \%$ \\
Paraná 1 * & 19,76 & $1,6 \%$ \\
Paraná 2** & 19,76 & $1,7 \%$ \\
\hline
\end{tabular}

Fonte: Dados da pesquisa.

* plantio convencional e colheita mecânica;

** plantio convencional e colheita manual. 
- Estudo da competitividade da produção de algodão entre Brasil

e Estados Unidos - safra 2003/04

Tabela 4. Custo de fertilizante - safra 2003/04

\begin{tabular}{|c|c|c|}
\hline Região & Custo (US\$/ha) & Custo fertilizante / custo total \\
\hline Estados Unidos & 85,10 & $6,9 \%$ \\
\hline Heartland & 98,47 & $8,2 \%$ \\
\hline Prairie Gateway & 31,48 & $4,1 \%$ \\
\hline Southern Seaboard & 125,11 & $10,1 \%$ \\
\hline Fruitful Rim & 98,67 & $5,5 \%$ \\
\hline Mississippi Portal & 115,32 & $7,7 \%$ \\
\hline Primavera do Leste & 294,72 & $16,9 \%$ \\
\hline Campo N. Parecis & 272,49 & $17,9 \%$ \\
\hline Paraná 1 * & 137,28 & $11,3 \%$ \\
\hline Paraná $2^{* *}$ & 137,28 & $11,7 \%$ \\
\hline
\end{tabular}

Fonte: Dados da pesquisa.

* plantio convencional e colheita mecânica;

** plantio convencional e colheita manual.

Tabela 5. Custo de químicos (herbicida, fungicida, inseticida e adjuvantes) - safra 2003/04

\begin{tabular}{lcc}
\hline Região & Custo (US\$/ha) & Custo químicos / custo total \\
\hline Estados Unidos & 162,61 & $13,2 \%$ \\
Heartland & 190,64 & $15,9 \%$ \\
Prairie Gateway & 69,56 & $9,0 \%$ \\
Southern Seaboard & 161,53 & $13,0 \%$ \\
Fruitful Rim & 218,11 & $12,2 \%$ \\
Mississippi Portal & 258,02 & $17,1 \%$ \\
Primavera do Leste & 624,44 & $35,9 \%$ \\
Campo N. Parecis & 570,13 & $37,5 \%$ \\
Paraná 1 * & 171,81 & $14,1 \%$ \\
Paraná 2 ** & 171,81 & $14,6 \%$ \\
\hline
\end{tabular}

Fonte: Dados da pesquisa.

* plantio convencional e colheita mecânica;

** plantio convencional e colheita manual.

Tabela 6. Custo de máquinas e equipamentos em geral - safra 2003/04

\begin{tabular}{lcc}
\hline Região & Custo (US\$/ha) & Custo máq. eq. / custo total \\
\hline Estados Unidos & 182,16 & $14,8 \%$ \\
Heartland & 118,68 & $9,9 \%$ \\
Prairie Gateway & 132,32 & $17,0 \%$ \\
Southern Seaboard & 140,75 & $11,3 \%$ \\
Fruitful Rim & 318,90 & $17,9 \%$ \\
Mississippi Portal & 212,75 & $14,1 \%$ \\
Primavera do Leste & 206,92 & $11,9 \%$ \\
Campo N. Parecis & 173,23 & $11,4 \%$ \\
Paraná 1 * & 285,04 & $23,4 \%$ \\
Paraná 2 ** & 137,35 & $11,7 \%$ \\
\hline
\end{tabular}

Fonte: Dados da pesquisa.

* plantio convencional e colheita mecânica;

** plantio convencional e colheita manual. 
Para o Brasil, as diferenças de valores entre as regiões estão relacionadas, principalmente, ao uso de máquinas e equipamentos de portes diferentes. Nem sempre, nas regiões mato-grossenses, por exemplo, em grandes áreas se utilizam máquinas e equipamentos de maiores potência e porte, respectivamente, com a eficiência necessária, comparativamente às regióes em que as máquinas e equipamentos são menores. Os dados coletados mostraram que em CNP há menor potência de máquinas em relação a PL, mas, mesmo assim, o tempo de execução dos serviços na cultura foi praticamente o mesmo entre as regiões, o que resultou em maior valor monetário para PL. Entretanto, a participação sobre o custo total não apresentou diferença entre as duas regiões. As regiões paranaenses, por sua vez, utilizam máquinas e equipamentos menores, que implicam em maior tempo na realização das tarefas, elevando o peso do custo das máquinas e equipamentos sobre o custo total. O sistema paranaense em que se considerou a colheita mecânica foi o de maior valor e peso sobre o custo total entre as regiões brasileiras.

No custo de oportunidade da terra, destaca-se a proximidade dos valores monetários entre a região de Prairie Gateway, em que se insere o estado do Texas, maior produtor dos EUA, e a região de $\mathrm{CNP}$, que vem apresentando aumento de área plantada em anos recentes (Tabela 7). As regiões de Fruitful Rim e Mississippi Portal apresentam um custo expressivamente maior que as do Brasil, provavelmente devido à maior tecnificação (grandes áreas) e ao uso intensivo de irrigação (70\% das áreas na região Fruitful Rim), que favorece uma maior produtividade por hectare, valorizando a terra. Esta também é uma das regiões mais desenvolvidas nos Estados Unidos. Em termos gerais, há menor participação desse item no custo total das regiões mato-grossenses do que nas norte-americanas. Nas paranaenses, foram observadas um dos maiores valores monetários e a maior participação sobre o custo total entre as regiões analisadas.

As diferenças do custo de oportunidade da terra entre as regiões brasileiras estão relacionadas à concorrência por área entre a cultura do algodão e as lavouras de grãos e de pecuária, principalmente. Em CNP, onde há maior disponibilidade de área para inserção da cultura do algodão e mais distante dos centros consumidores, o valor do arrendamento, utilizado como proxy para o cálculo deste item, é menor que nas demais regiões. 
Entre as regiões norte-americanas, as diferenças estão relacionadas, por sua vez, além da maior possibilidade de obtenção de produção mais elevada, devido à maior produtividade, aos subsídios governamentais direcionados aos produtores agrícolas, entre eles o algodão. Como há transferência de recursos para os proprietários de terra, seu valor e o arrendamento tende a aumentar. A essas considerações, acrescenta-se a pouca disponibilidade de novas áreas aptas ao cultivo de algodão nos EUA.

No custo com mão-de-obra, foram incluídos os valores pagos aos trabalhadores temporários, assim como para os trabalhadores considerados fixos. Neste último caso, os custos trabalhistas estão inclusos. Para os Estados Unidos, os dados do USDA (2006a) consideram também o custo de oportunidade da mão-de-obra familiar ${ }^{8}$.

No geral, entre todas as regiões, a maioria dos valores está relativamente próxima entre si, mas os maiores valores e participações sobre o custo total são obtidos nas regiões norte-americanas. Destacam-se, entretanto, os valores díspares da região Paraná 2, onde se utiliza a colheita manual, e a região Fruitful $\operatorname{Rim}^{9}$ (Tabela 8). Para o sistema Paraná 2 , inclusive os pagamentos efetuados aos trabalhadores que realizaram a colheita manual foram incorporados como mão-de-obra contratada, o que elevou o valor deste item. Já em Fruitful Rim, está inclusa a região da Flórida, uma das mais desenvolvidas nos Estados Unidos, o que contribui para que o custo da mão-de-obra se eleve, devido à concorrência entre as demais atividades da região.

O custo do beneficiamento foi computado como o do serviço terceirizado nas regióes, muitas vezes tendo como pagamentos o caroço de algodão acrescido de um percentual de algodão em pluma. Em termos de custos por hectare, os dados mostram vantagens para as regiões brasileiras, que perdem apenas para a região Prairie Gateway, que apresenta o menor custo por hectare entre as analisadas. Neste caso, a influência é da baixa produtividade da mesma.

\footnotetext{
${ }^{8}$ Segundo o USDA (2006a), o trabalho familiar, ou trabalho não pago, foi computado com o objetivo de mensurar o custo de oportunidade dos trabalhadores não assalariados que estão na fazenda. Os valores representaram entre $4 \%$ e $12 \%$ do custo total. O custo foi obtido com base no salário que o trabalhador teria em outra ocupação fora da fazenda. Contudo, os dados detalhados não foram divulgados pela fonte dos dados tomados como base neste trabalho.

${ }^{9}$ Não foi possível a obtenção da quantidade e do valor da mão-de-obra de forma desagregada para as regiões norte-americanas.
} 
Ao analisar o custo de beneficiamento por unidade produzida, tanto em termos de algodão em caroço quanto de algodão em pluma, os menores custos são obtidos, respectivamente, em: PL, CNP, PR1, PR2, Heartland, Mississippi Portal, Fruitful Rim, EUA, Prairie Gateway e Sourthern Seaboard. Assim, pode-se dizer que é boa a competitividade brasileira. Esse fator torna-se destaque quando se compara sua participação no custo total das regiões de PL e CNP com as demais (Tabela 9).

Para o cômputo dos juros sobre capital de máquinas e equipamentos nas regiões brasileiras, optou-se por considerar a taxa para obtenção de crédito por meio do Programa de Modernização da Frota de Tratores Agrícolas e Implementos Associados e Colheitadeiras (Moderfrota). De acordo com as normas para disponibilidade de crédito, que é baseada na renda agropecuária bruta anual do produtor, a taxa de juro adotada para as regiões de PL e CNP foi de 12,75\% ao ano e para as regiões paranaenses, de $9,75 \%$ ao ano. Conforme os dados da Tabela 10, este item possui um pequeno peso no custo total de produção das brasileiras. Nas regióes norte-americanas, sua participação é expressiva. Entretanto, os valores para estas últimas regiões não foram calculados pelos autores, mas utilizados os divulgados pelo USDA (2006a).

Tabela 7. Custo de oportunidade da terra - safra 2003/04

\begin{tabular}{lcc}
\hline Região & Custo (US\$/ha) & Custo terra / custo total \\
\hline Estados Unidos & 130,22 & $10,6 \%$ \\
Heartland & 138,40 & $11,5 \%$ \\
Prairie Gateway & 67,14 & $8,6 \%$ \\
Southern Seaboard & 114,90 & $9,2 \%$ \\
Fruitful Rim & 196,37 & $11,0 \%$ \\
Mississippi Portal & 189,03 & $12,6 \%$ \\
Primavera do Leste & 138,30 & $8,0 \%$ \\
Campo N. Parecis & 69,15 & $4,5 \%$ \\
Paraná 1 & 163,00 & $13,4 \%$ \\
Paraná 2 & 163,00 & $13,9 \%$ \\
\hline
\end{tabular}

Fonte: Dados da pesquisa.

* plantio convencional e colheita mecânica;

** plantio convencional e colheita manual. 
Tabela 8. Custo da mão-de-obra - safra 2003/04

\begin{tabular}{|c|c|c|}
\hline Região & Custo (US\$/ha) & Custo m-d-o / custo total \\
\hline Estados Unidos & 124,39 & $10,1 \%$ \\
\hline Heartland & 87,84 & $7,3 \%$ \\
\hline Prairie Gateway & 119,89 & $15,4 \%$ \\
\hline Southern Seaboard & 109,59 & $8,8 \%$ \\
\hline Fruitful Rim & 197,26 & $11,1 \%$ \\
\hline Mississippi Portal & 101,38 & $6,7 \%$ \\
\hline Primavera do Leste & 81,78 & $4,7 \%$ \\
\hline Campo N. Parecis & 75,73 & $5,0 \%$ \\
\hline Paraná 1 * & 88,36 & $7,3 \%$ \\
\hline Paraná $2^{* *}$ & 216,08 & $18,4 \%$ \\
\hline
\end{tabular}

Fonte: Dados da pesquisa.

* plantio convencional e colheita mecânica;

** plantio convencional e colheita manual.

Tabela 9. Custo do beneficiamento - safra 2003/04

\begin{tabular}{lcc}
\hline Região & Custo (US\$/ha) & Custo benefic. / custo total \\
\hline Estados Unidos & 218,26 & $17,8 \%$ \\
Heartland & 231,01 & $19,3 \%$ \\
Prairie Gateway & 105,58 & $13,6 \%$ \\
Southern Seaboard & 267,61 & $21,5 \%$ \\
Fruitful Rim & 319,00 & $17,9 \%$ \\
Mississippi Portal & 270,05 & $17,9 \%$ \\
Primavera do Leste & 100,85 & $5,8 \%$ \\
Campo N. Parecis & 107,13 & $7,0 \%$ \\
Paraná 1 * & 165,73 & $13,6 \%$ \\
Paraná 2 ** & 138,11 & $11,7 \%$ \\
\hline
\end{tabular}

Fonte: Dados da pesquisa.

* plantio convencional e colheita mecânica;

** plantio convencional e colheita manual.

Tabela 10. Juros de capital de máquinas e equipamentos - safra 2003/04

\begin{tabular}{lcc}
\hline Região & Custo (US\$/ha) & Custo juros / custo total \\
\hline Estados Unidos & 154,31 & $12,6 \%$ \\
Heartland & 148,01 & $12,3 \%$ \\
Prairie Gateway & 138,62 & $17,8 \%$ \\
Southern Seaboard & 143,02 & $11,5 \%$ \\
Fruitful Rim & 193,97 & $10,9 \%$ \\
Mississippi Portal & 163,40 & $10,9 \%$ \\
Primavera do Leste & 26,38 & $1,5 \%$ \\
Campo N. Parecis & 22,09 & $1,5 \%$ \\
Paraná 1 * & 27,79 & $2,3 \%$ \\
Paraná 2 ** & 13,39 & $1,1 \%$ \\
\hline
\end{tabular}

Fonte: Dados da pesquisa.

* plantio convencional e colheita mecânica;

** plantio convencional e colheita manual. 
Por outro lado, é expressiva a diferença dos valores dos juros sobre os insumos operacionais entre os dois países. Nos EUA, esse item representa $0,2 \%$ do custo total, enquanto, no Brasil, esse custo chega a ter uma participação de $7,2 \%$ (Tabela 11). Isso já era esperado, devido às taxas altas de juros utilizadas no Brasil.

Vale ressaltar, entretanto, a diferença entre as taxas de juros básicas que vigoram nos dois países sob análise, que influenciam a captação de recursos para investimentos agrícolas. No período entre o início de 2000 e final de 2004, observa-se, pela Figura 1, uma situação de aparente relação inversa entre as duas taxas. Enquanto a taxa Selic média no período considerado foi de $18,83 \%$ a.a., nos EUA a média foi de $2,86 \%$ a.a..

Outros gastos também foram computados, mas que possuem pouca participação sobre custo total de cada região. Assim, optou-se por não analisar as diferenças entre as regiões. Os gastos se referem aos custos com água para irrigação, nos EUA, administrações gerais da fazenda e taxas diversas e seguros.

Figura 1. Evolução das taxas de juros diárias no Brasil e nos EUA 01/01/2000-31/12/2004

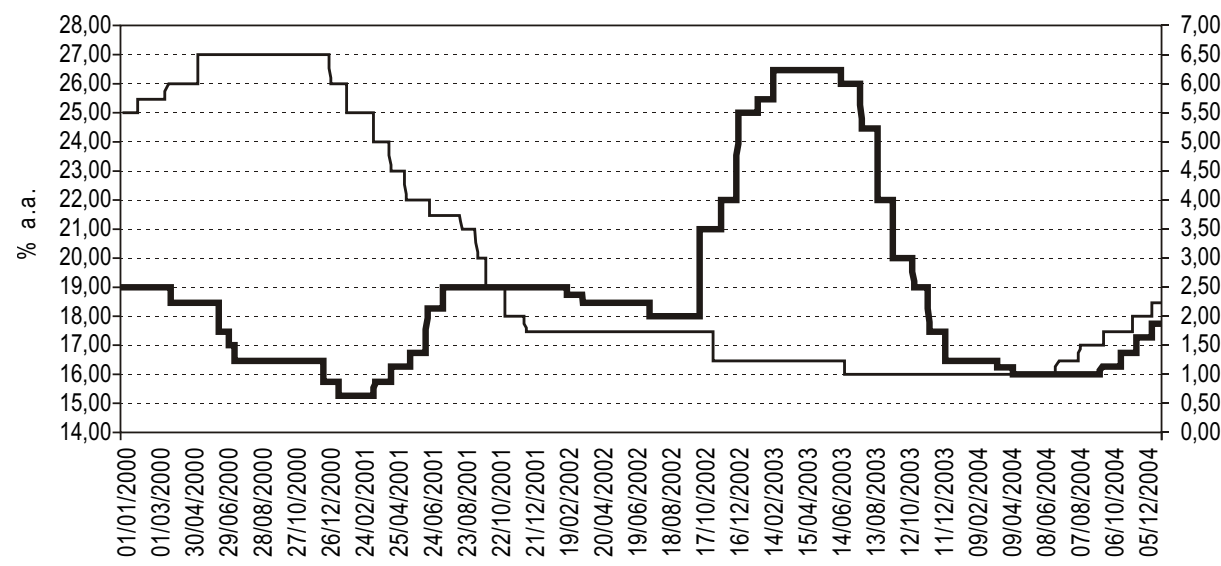

Fonte: Instituto de Pesquisa Econômica Aplicada - IPEA (2006)

Obs.: Selic $=$ Taxa de juros - Selic - fixada pelo Copom (\% a.a.). Decisões da reunião do Comitê de Política Monetária (Copom) para a taxa de juros referencial (Selic).

EUA $=$ Estados Unidos - taxa de juros básica - Federal Funds - fixada pelo Federal Open Market Committee (FOMC) - (\% a.a.). Decisões da reunião do Comitê Federal do Mercado Aberto para a taxa de juros básica Federal Funds. 
Separando todos os custos supracitados entre variáveis e fixos, observa-se, na Tabela 12 e na Tabela 13, que há maior peso dos custos variáveis sobre o total em todas as regiões pesquisadas, com destaque para as do Brasil. Os custos variáveis representam entre $55 \%$ e $84 \%$ do custo nas regiões brasileiras e entre 53\% e 66\% nas dos EUA. Já a participação dos custos fixos oscila de $16 \%$ a $45 \%$ no Brasil e de $34 \%$ a $47 \%$ nos EUA.

A soma dos custos supracitados resulta nos valores apresentados na Figura 2, em US\$/ha. Conforme se observa, os maiores custos por hectare são obtidos nas regiões brasileiras (PL e CNP) e norte-americanas (Fruitful Rim e Mississippi Portal). Entretanto, são as que apresentam as maiores produtividades médias.

Contudo, a competitividade deve ser analisada por meio do custo unitário da pluma na fazenda ${ }^{10}$. No Brasil, o menor custo foi da região de CNP (US\$ 0,4855/lp), que é 13\% menor que o mais baixo custo unitário da região Heartland (US\$ 0,5623/lp), pertencente aos EUA (Figura 3). Já o custo unitário da região do Paraná com colheita manual, de maior custo brasileiro (US\$ 0,6093/lp), é 31\% menor que o custo unitário da região Prairie Gateway, de maior custo dos EUA (US\$ 0,8879/lp).

Esses resultados contribuem para uma margem positiva de todas as regiões brasileiras, enquanto que a média para os EUA e da região Prairie Gateway foram negativas. Entre as regiões americanas, somente Heartland e Fruitful Rim apresentaram maiores margens que PL e Paraná, com colheita manual, as menores entre as do Brasil (Figura 4). Observa-se a forte correlação dessa margem com a produtividade agrícola obtida. Mesmo assim, em Mississippi Portal foi considerada a segunda maior produtividade agrícola nos EUA, entretanto, sua margem foi uma das menores entre as regiões analisadas.

${ }^{10}$ 10. Para o cálculo do custo unitário, foram utilizadas as seguintes quantidades de algodão em pluma, em libra-peso (lp): Primavera do Leste: 3.095,26 lp; Campo Novo do Parecis: 3.224,23 lp; Paraná 1: 2.380,97 lp; Paraná 2: 1.984,14 lp; Estados Unidos: 1.833,38 lp; Heartland: 2.133,18 lp; Prairie Gateway: 875 lp; Southern Seaboard: 2.053,18 lp; Fruitful Rim: 2.695,75 lp; e, Mississippi Portal: 2.385 lp. 
Tabela 11. Juros de financiamento de capital de giro (sobre os insumos) - safra 2003/04

\begin{tabular}{lcc}
\hline Região & Custo (US\$/ha) & Custo juros financ / custo total \\
\hline Estados Unidos & 2,82 & $0,2 \%$ \\
Heartland & 2,77 & $0,2 \%$ \\
Prairie Gateway & 1,00 & $0,1 \%$ \\
Southern Seaboard & 2,77 & $0,2 \%$ \\
Fruitful Rim & 4,00 & $0,2 \%$ \\
Mississippi Portal & 3,78 & $0,3 \%$ \\
Primavera do Leste & 121,01 & $7,0 \%$ \\
Campo N. Parecis & 110,13 & $7,2 \%$ \\
Paraná 1 & 40,29 & $3,3 \%$ \\
Paraná 2 & 40,29 & $3,4 \%$ \\
\hline
\end{tabular}

Fonte: Dados da pesquisa.

* plantio convencional e colheita mecânica;

** plantio convencional e colheita manual.

Tabela 12. Custo total variável - safra 2003/04

\begin{tabular}{lcc}
\hline Região & Custo (US\$/ha) & Custo variável / custo total \\
\hline Estados Unidos & 751,89 & $61,3 \%$ \\
Heartland & 756,68 & $63,1 \%$ \\
Prairie Gateway & 411,75 & $53,0 \%$ \\
Southern Seaboard & 793,72 & $63,8 \%$ \\
Fruitful Rim & $1.081,57$ & $60,6 \%$ \\
Mississippi Portal & 989,03 & $65,7 \%$ \\
Primavera do Leste & $1.409,80$ & $81,0 \%$ \\
Campo N. Parecis & $1.283,30$ & $84,3 \%$ \\
Paraná 1 * & 819,91 & $67,4 \%$ \\
Paraná 2 ** & 644,59 & $54,8 \%$ \\
\hline
\end{tabular}

Fonte: Dados da pesquisa.

* plantio convencional e colheita mecânica;

** plantio convencional e colheita manual.

Tabela 13. Custo total fixo (mão-de-obra, terra, juros máquinas e equipamentos, administração da fazenda, assistência técnica, CESSR) - safra 2003/04

\begin{tabular}{lcc}
\hline Região & Custo (US\$/ha) & Custo fixo / custo total \\
\hline Estados Unidos & 475,54 & $38,7 \%$ \\
Heartland & 442,75 & $36,9 \%$ \\
Prairie Gateway & 365,13 & $47,0 \%$ \\
Southern Seaboard & 449,69 & $36,2 \%$ \\
Fruitful Rim & 702,57 & $39,4 \%$ \\
Mississippi Portal & 515,99 & $34,3 \%$ \\
Primavera do Leste & 329,84 & $19,0 \%$ \\
Campo N. Parecis & 238,87 & $15,7 \%$ \\
Paraná 1 * & 396,24 & $32,6 \%$ \\
Paraná 2 ** & 530,94 & $45,2 \%$ \\
\hline
\end{tabular}

Fonte: Dados da pesquisa.

* plantio convencional e colheita mecânica;

** plantio convencional e colheita manual. 
- Estudo da competitividade da produção de algodão entre Brasil

e Estados Unidos - safra 2003/04

Figura 2. Custo total por hectare - em US\$ - safra 2003/04

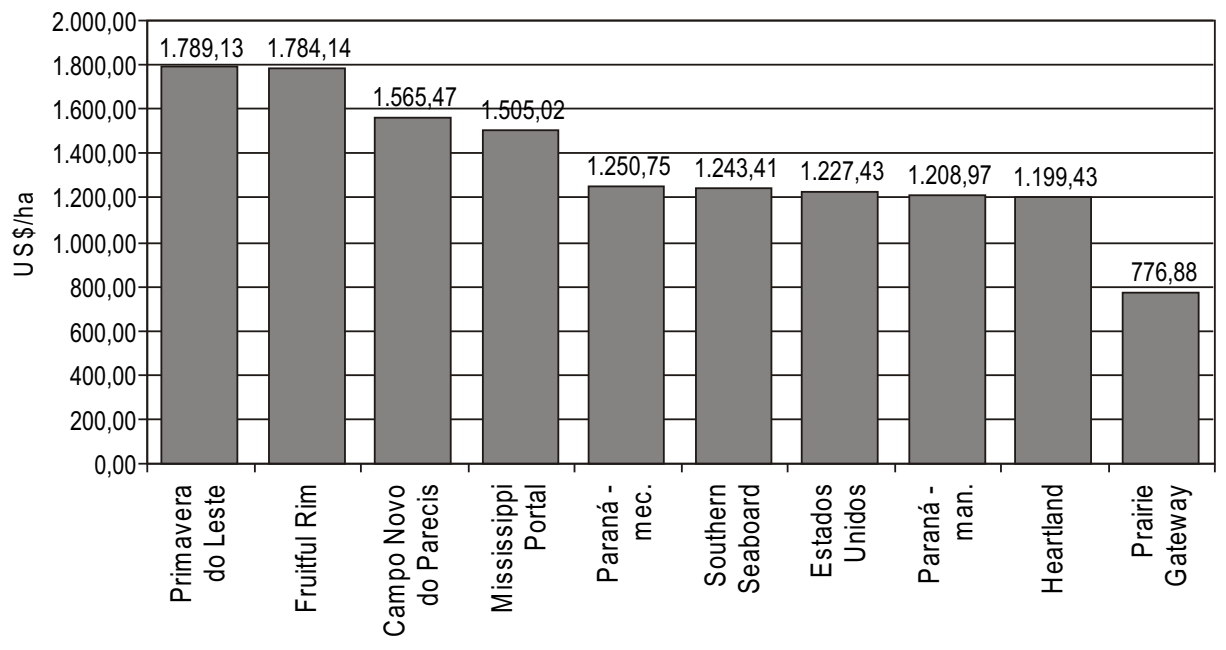

Fonte: Dados da pesquisa

Figura 3. Custo em US\$/lp - safra 2003/04

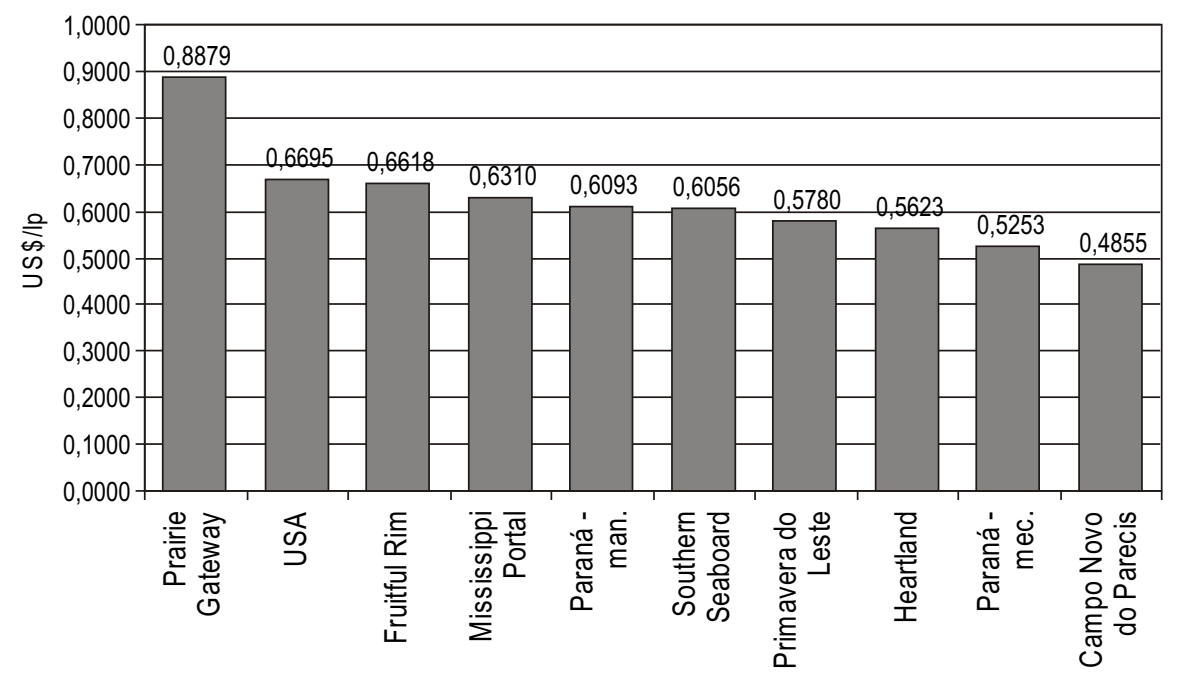

Fonte: Dados da pesquisa 
Figura 4. Rentabilidade média da produção de algodão em pluma nas regiões pesquisadas, sem subsídio - safra 2003/04

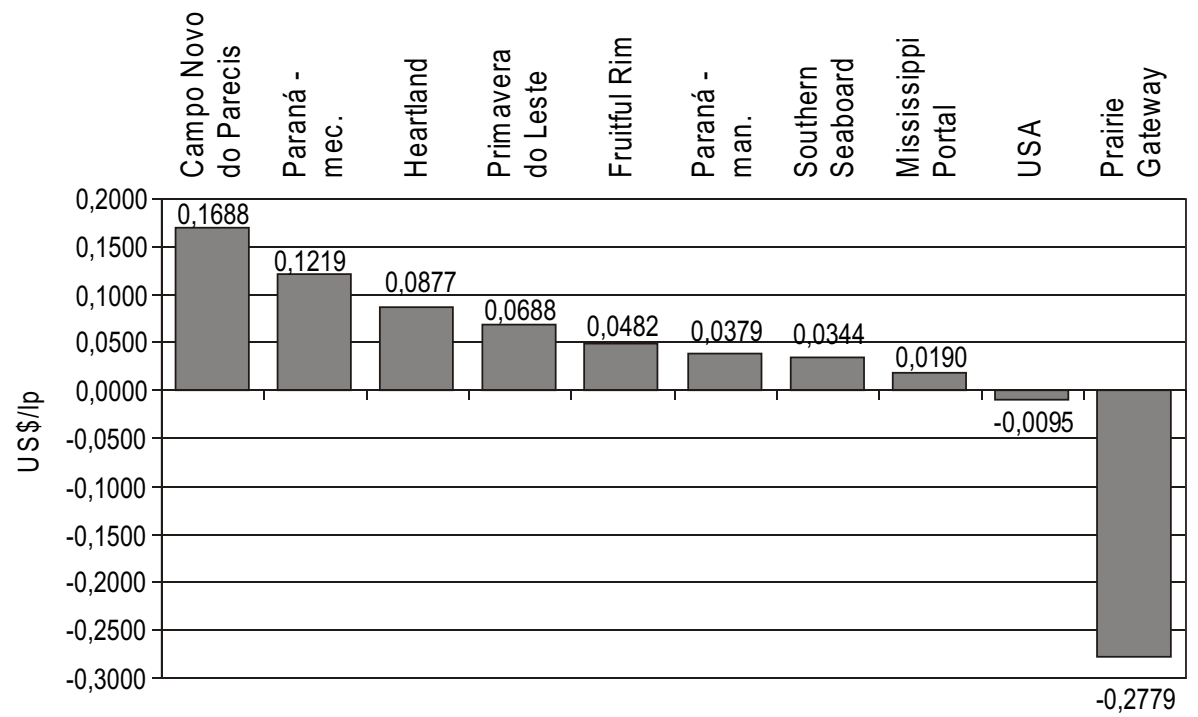

Fonte: Dados da pesquisa

Figura 5. Rentabilidade média na produção de algodão em pluma nas regiões pesquisadas, com subsídio - safra 2003/04

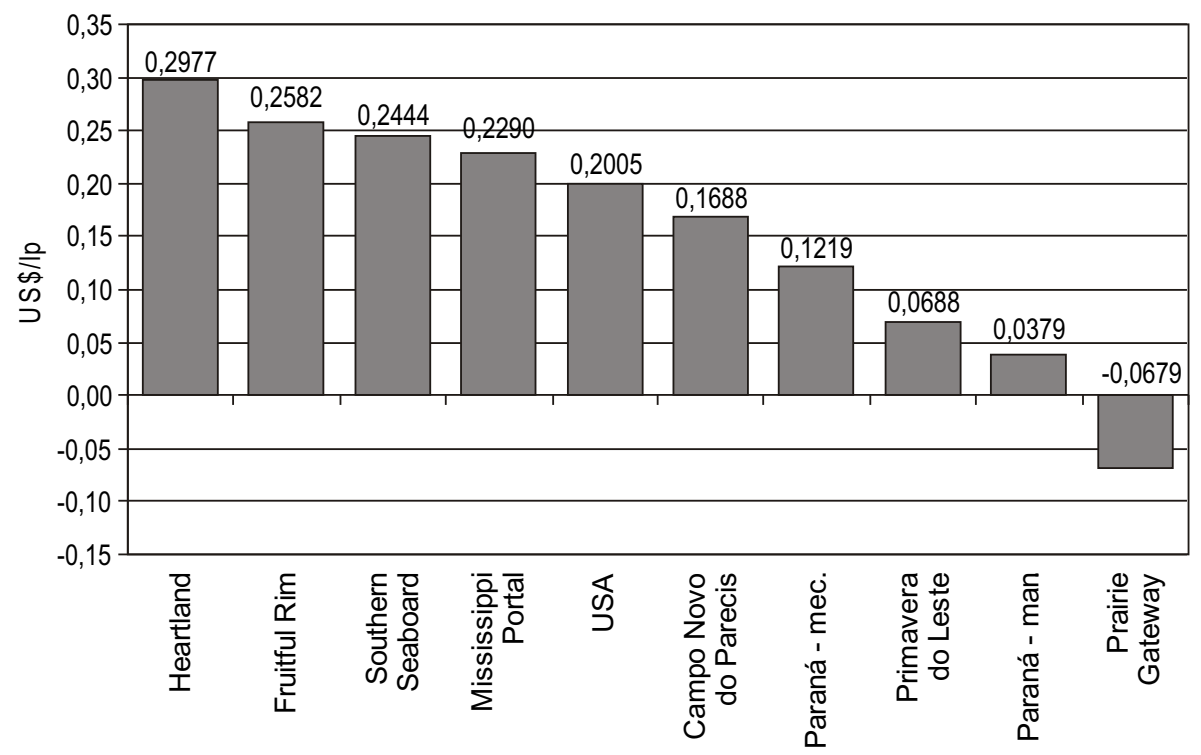

Fonte: Dados da pesquisa 
- Estudo da competitividade da produção de algodão entre Brasil e Estados Unidos - safra 2003/04

Com a maioria das regiões norte-americana apresentando margens apertadas e com a margem média para o país sendo negativa, já se pode refletir em que base está ocorrendo o crescimento da produção de algodão nos EUA. Em seguida, serão analisados alguns aspectos dos subsídios para o algodão naquele país.

\subsection{A influência dos subsídios norte-americanos sobre a rentabilidade de produtores}

Alguns aspectos dos subsídios norte-americanos à produção e à exportação podem ser destacados, os quais visam estabilizar e sustentar a renda de produtores, em face às flutuações negativas de preços causadas por oscilações das condições de oferta e demanda mundial. Segundo Womach (2004), entre os subsídios, há os programas de suporte de preços, que incluem: a) empréstimo de assistência para comercialização, b) pagamentos diretos, c) pagamentos "counter-cyclical" e d) pagamento de mercado.

Há também a assistência de perda de safra, causada por desastres naturais, como seca, inundação, doenças e pragas em geral. Para essas assistências, há o seguro agrícola. Para a sustentação da renda agrícola, outros programas de suportes são ainda acionados quando os preços domésticos dos EUA estão menos competitivos no mercado internacional, possibilitando que produtores vendam a pluma a preços menores, recebendo a diferença do governo. Os programas para esta situação são: a) Step 1 (taxa de redução de reembolso de empréstimo), b) Step 2 (pagamento para indústrias e exportadores domésticos), c) Step 3 (quotas especiais de importação) e, d) quota de limite global de importação. Outro sistema de ajuda aos produtores é a assistência à exportação. Aqui se enquadram: a) garantia de crédito à exportação, b) programa de desenvolvimento do mercado externo, e c) programa de acesso ao mercado.

Segundo Womach (2004), entre os anos agrícolas de 1991 a 2003, produtores norte-americanos receberam, em média, US\$1,761 milhão anuais em subsídios diretos dos programas de sustentação de renda e preços e de perda de safra. Ponderados pela quantidade produzida, entre 1991 e 2003, os subsídios diretos representaram, em média, US\$ 0,21/lp ao ano. Do programa de sustentação de renda e preços, os pagamentos diretos foram, em média, de US\$ 0,17/lp ao ano e, dos subsídios de perda 
de safra, de US\$ 0,04/lp. Vale destacar que, pela ausência de informações detalhadas, aqui se incluem somente os pagamentos diretos, não considerando os gastos e impactos dos demais programas.

Os subsídios no montante médio de US\$ 0,21/lp ao ano representam aproximadamente $31,4 \%$ do custo médio nos EUA, tomando como base o custo em US\$/lp da safra 2003/04 apresentado neste trabalho. Em nível regional, esses repasses representam $37 \%$ do custo médio da região Heartland, 24\% da região Prairie Gateway, 35\% da região Southern Seaboard, 32\% da região Fruitful Rim e 33\% do custo médio da região Mississippi Portal.

Considerando o subsídio médio anual de US\$ 0,21/lp para todas as regiões dos EUA, observa-se, na Figura 5, que as margens em US $\$ / 1 p$ passam a ser positivas na maioria das regiões, com exceção da região Prairie Gateway. A maior margem ocorre na região Heartland, devido à produtividade de pluma por hectare, seguida das regiões Fruitful Rim, Southern Seaboard e Mississippi Portal. Com este patamar de rentabilidade, a lucratividade das regióes brasileiras é maior apenas que a média verificada em Prairie Gateway.

\section{Considerações Finais}

O objetivo deste trabalho foi analisar a competitividade da produção de algodão entre Brasil e Estados Unidos da América, com base nos custos de produção agrícola nas principais regiões produtoras, tomando como referência a safra 2003/04.

Inicialmente, vale destacar os itens de maiores pesos no custo total no Brasil e nos EUA. Neste último, destacam-se os custos beneficiamento, com máquinas (depreciação, conservação, combustível e lubrificante), com defensivos químicos, juros de capital de máquinas e equipamentos, com mão-de-obra, incluindo a contratada e familiar e com o custo de oportunidade da terra. No Brasil, merecem destaques os gastos com defensivos químicos, fertilizantes, máquinas (depreciação, conservação, combustível e lubrificante) e o custo de oportunidade da terra.

Os autores deste trabalho reconhecem a dificuldade de se efetuar a comparação dos custos de produção entre os dois países, devido, principalmente, aos diferentes sistemas considerados, assim como ao pouco detalhamento dos dados norte-americanos, que dificultou análises de quantidade e de preços praticados. Contudo, o objetivo era apresentar 
as principais diferenças e estruturas de custos entre os dois países, assim como a relação de rentabilidade entre os mesmos.

Diante disso, alguns apontamentos podem ser realçados. Os dados mostraram maior competitividade do Brasil, frente aos EUA, com alta produtividade, mas com custos considerados altos por hectare. Assim, a cultura mostra riscos elevados (problemas climáticos, grande volume de recursos financeiros em capital de giro e fixos, entre outros), agravados pelas margens estreitas, pelos investimentos em capitais necessários para a cultura (sunk cost) - em que boa parte é específica para a cultura do algodão - e pela necessidade de se buscar melhoramentos nos processos produtivos que visem aumentar a rentabilidade. Como a produtividade está oscilando e apresenta sinais de menor crescimento nos últimos anos, é preciso que o produtor busque o ajustamento de uso de insumos para manter a rentabilidade da atividade, não necessariamente maior produtividade.

Desta forma, a questão e o desafio que se colocam para o setor são: como aumentar a produtividade e/ou diminuir os custos, em especial os variáveis, para melhorar a competitividade e garantir a sobrevivência do setor num contexto internacional? A produtividade do algodão brasileiro já é uma das maiores do mundo e, portanto, poderá haver dificuldade em obter progressos significativos nesta variável. Assim, parece estar no controle e/ou redução dos custos o maior desafio dos produtores brasileiros para as próximas safras, no intuito de manter a competitividade e a renda. Como citado anteriormente, são os custos variáveis os de maior peso sobre a cultura, o qual deverá ser o foco de pesquisas futuras.

Para os EUA, os dados mostraram menor produtividade e custos relativamente altos, que culminaram em margens negativas para algumas regiões. Dessa forma, aparentemente, a sustentabilidade do setor algodoeiro daquele país é artificial, dependente da ajuda governamental ao produtor e para a comercialização em geral. Isso gera impacto negativo sobre preços para os demais países, comprovados por autores como Summer (2005), Pan et al. (2004) e Poonyth, Sharmand, Shui (2004), o que levanta dúvidas sobre as perspectivas, tanto para os EUA quanto para outros países, se houver redução dos subsídios determinados pela Organização Mundial do Comércio (OMC).

E, finalmente, os custos unitários obtidos neste estudo são relativamente altos, quando comparados aos níveis de preços históricos. 
Assim, novos investimentos em tecnologia que reduzam ainda mais os custos de produção devem ser executados, mantendo a competitividade principalmente dos países em desenvolvimento.

\section{Referências Bibliográficas}

ALVES, L.R.A. A reestruturação da cotonicultura no Brasil: fatores econômicos, institucionais e tecnológicos. 2006. 121 p. Tese (Doutorado em Economia Aplicada) - Escola Superior de Agricultura "Luiz de Queiroz", Universidade de São Paulo. Piracicaba, 2006.

BARROS, G.S.C. Economicidade e sustentabilidade da agropecuária. Piracicaba, SP, 2007 (mimeografado).

BROOKS, N.L. Characteristics and production costs of U.S. cotton farms. Estatistical bulletin. N.974-2, Oct./2001.

CENTRO DE ESTUDOS AVANÇADOS EM ECONOMIA APLICADA CEPEA/ESALQ/USP. Indicadores de preços. 2005.

COUTINHO, L. et al. Estudo da competitividade da indústria brasileira. IE-Unicamp. IEI-UFRJ. FUNCEX. Fund. Dom Cabral. Campinas. 1993.

DE ZEN, S.; PERES, F.C. Painel agrícola como instrumento de comunicação. In: CONGRESSO BRASILEIRO DE ECONOMIA E SOCIOLOGIA RURAL, 40., Passo Fundo, 2002. Anais. Brasília: SOBER, 2002.

INSTITUTO BRASILEIRO DE GEOGRAFIA E ESTATÍSTICA - IBGE. SIDRA. AGRICULTURA. Disponível em: $<$ http://www.sidra.ibge.gov.br/bda/tabela/listabl3.asp?c $=1612 \& n=0 \& u$ $=0 \& z=t \& o=11 \& i=P>$. Acesso em: jul. 2005.

INSTITUTO DE PESQUISA ECONÔMICA APLICADA - IPEA. IPEADATA. Disponível em: <http://www.ipeadata.gov.br $>$. Acesso em: jul. 2006.

KUPFER, D. Uma abordagem neo-schumpeteriana da competitividade industrial. Ensaios FEE, Porto Alegre: FEE, v. 17, n. 1, p. 355-372, 1996.

MÜLLER, G. A conceitualização de competitividade: um exercício metodológico. OLAM (Rio Claro), v. 6, p. 11-21, 2006. 
PAN, et al. The impacts of U.S. cotton programs on the world market: an analysis of Brazilian and African WTO petitions. Texas Tech University. January 2004.

PLAXICO, J.S.; TWEETEN, L.G. Representative farms for policy and projection research. Journal of Farm Economics. December, 1963.

POONYTH, D.; SHARMAND, R.; SHUI, S. The impacts of domestic and trade policies on the world cotton market. Fao commodity and trade policy research working paper, n.8, April, 2004.

SUMMER, D. A quantitative simulation analysis of the impacts of U.S. cotton subsidies on cotton prices and quantities. Disponível em: <http://www.fao.org/es/esc/common/ecg/ 47647_en_Sumner.pdf $>$. Acesso em: jan. 2005.

UNITED STATES DEPARTMENT OF AGRICULTURE - USDA. Economic research service. Farm economy. Costs of production. Disponível em: < http://www.ers.usda.gov>. Acesso em: jul. 2006a.

UNITED STATES DEPARTMENT OF AGRICULTURE - USDA. Economic research service. Farm practices \& management. Disponível em: <http://www.ers.usda.gov>. Acesso em: jul. 2006b.

UNITED STATES DEPARTMENT OF AGRICULTURE - USDA. Farm resource regions. Economic research service. Agriculture information bulletin. $\mathrm{n} .760$, Sep./2000.

VAN DUREN, E.; MARTIN, L.; WESTGREN, R. A framework for assessing national competitiveness and the role of private strategy and public policy. In.; Competitiveness in International Food Markets, Westview Press, San Francisco, 1994. 343 p.

WOMACH, J. Cotton production and support in the United States. Congressional Research Service. CRS report for Congress. June 24, 2004. Order Code RL32442. 